OPEN ACCESS

Edited by:

Inna Lermontova,

Institute of Plant Genetics and Crop Plant Research, Germany

Reviewed by:

Célia Baroux

University of Zürich, Switzerland

Stefan Heckmann,

University of Birmingham, UK

*Correspondence:

Aline V. Probst

aline.probst@univ-bpclermont.fr

${ }^{\dagger}$ These authors have contributed equally to this work.

Specialty section: This article was submitted to Plant Cell Biology,

a section of the journal

Frontiers in Plant Science

Received: 29 August 2015 Accepted: 09 November 2015 Published: 30 November 2015

Citation:

Simon L, Voisin M, Tatout C and Probst AV (2015) Structure

and Function of Centromeric and Pericentromeric Heterochromatin

in Arabidopsis thaliana.

Front. Plant Sci. 6:1049.

doi: $10.3389 / \mathrm{fp} / \mathrm{s.2015.01049}$

\section{Structure and Function of Centromeric and Pericentromeric Heterochromatin in Arabidopsis thaliana}

\author{
Lauriane Simon ${ }^{\dagger}$, Maxime Voisin ${ }^{\dagger}$, Christophe Tatout and Aline V. Probst ${ }^{*}$ \\ CNRS UMR6293, INSERM U1103, Clermont University, GReD, Aubière, France
}

The centromere is a specific chromosomal region where the kinetochore assembles to ensure the faithful segregation of sister chromatids during mitosis and meiosis. Centromeres are defined by a local enrichment of the specific histone variant $\mathrm{CenH} 3$ mostly at repetitive satellite sequences. A larger pericentromeric region containing repetitive sequences and transposable elements surrounds the centromere that adopts a particular chromatin state characterized by specific histone variants and post-translational modifications and forms a transcriptionally repressive chromosomal environment. In the model organism Arabidopsis thaliana centromeric and pericentromeric domains form conspicuous heterochromatin clusters called chromocenters in interphase. Here we discuss, using Arabidopsis as example, recent insight into mechanisms involved in maintenance and establishment of centromeric and pericentromeric chromatin signatures as well as in chromocenter formation.

Keywords: centromere, chromocenter, histone variants, 3D nucleus, lamina, nuclear envelope

Centromeres are essential chromosomal structures that were first defined as central restrictions of the mitotic chromosomes that function in chromosome segregation during cell division. Except for Saccharomyces cerevisiae, centromeres are not defined genetically by a specific DNA sequence but rather epigenetically by a particular chromatin environment and the presence of the specific histone variant $\mathrm{CenH} 3$. The centromeric and the surrounding pericentromeric chromosomal regions form heterochromatin domains that remain condensed during interphase (Heitz, 1928) and in some species like Arabidopsis thaliana these are clustered into chromocenter structures (Figure 1; Fransz et al., 2002). Here we discuss our current knowledge concerning sequence composition, chromatin features and interphase higher-order organization of centromeric and pericentromeric regions into chromocenters, referring to the centromeric region specifically as the part of the chromosome involved in kinetochore formation, while we refer to the pericentromeric domains as the adjacent chromatin regions (according to Gent and Dawe, 2011).

\section{SEQUENCE COMPOSITION OF ARABIDOPSIS CENTROMERIC AND PERICENTROMERIC REGIONS}

Centromeric sequences consist in most organisms of short repetitive DNA sequences arranged in tandem and/or transposable elements (Plohl et al., 2014). New centromeres can emerge from anonymous sequences but they gradually incorporate repetitive arrays (Han et al., 2009; Plohl et al., 2014) suggesting that DNA repeats may be a preferred DNA environment for centromere formation. In A. thaliana, centromeric regions mainly consist of a 178 bp long sequence also called AtCon, pAL1, 


\section{A}

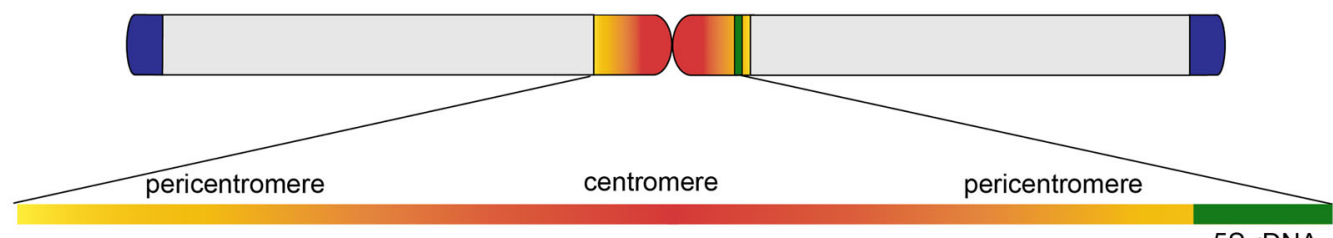

5S rDNA
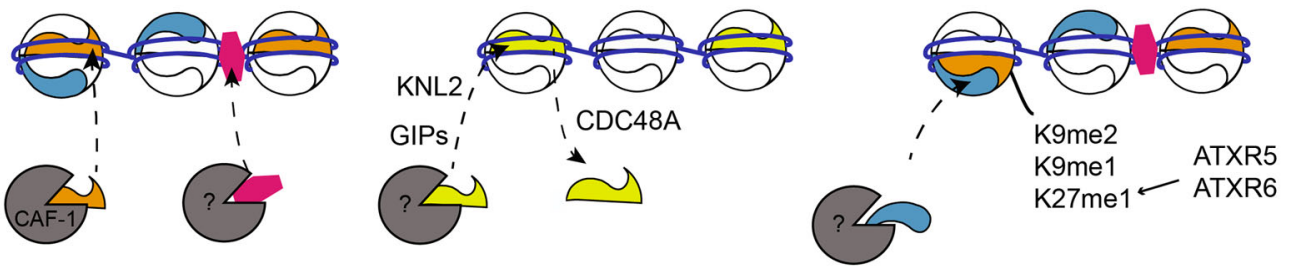

$\curvearrowright_{\mathrm{H} 3.1-\mathrm{H} 4} \bigodot_{\mathrm{CenH} 3-\mathrm{H} 4} \overbrace{\mathrm{H} 2 \mathrm{~A} . \mathrm{W}-\mathrm{H} 2 \mathrm{~B}}^{\mathrm{H} 1}$

B

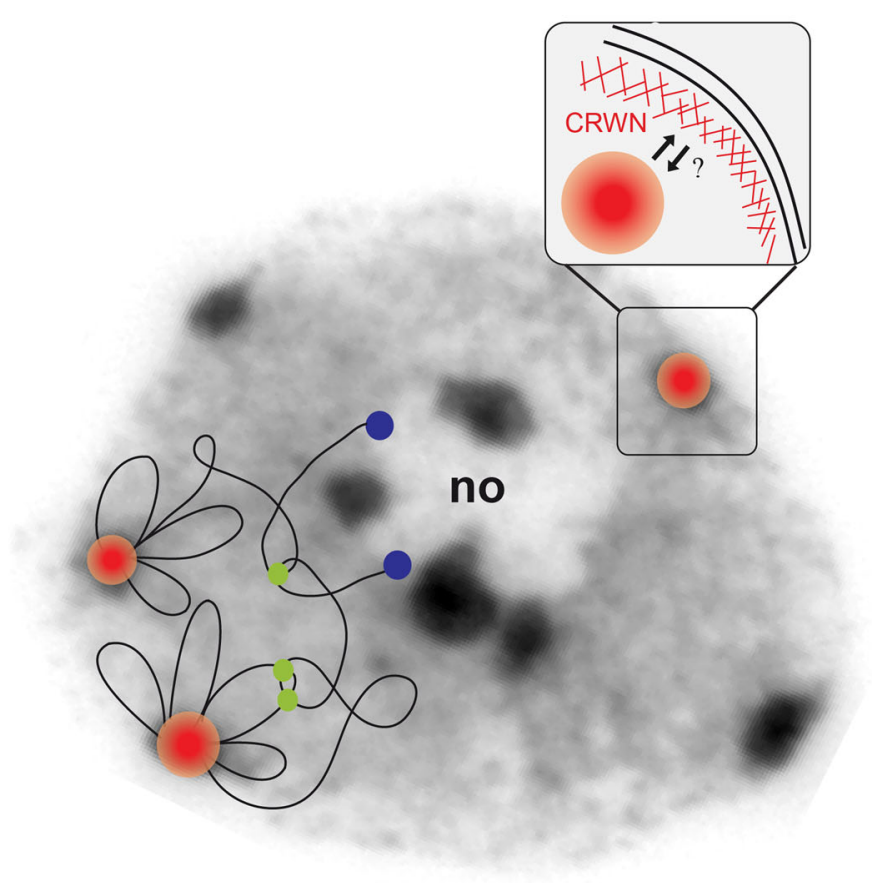

chromocenter IHI/KEE telomere

FIGURE 1 | (A) Model of an Arabidopsis thaliana chromosome. Enlargement of the central part of a chromosome (top) shows the sequence composition of the centromeric (red, mainly consisting of repetitive $180 \mathrm{bp}$ repeats) and the pericentromeric region (orange, containing interspersed repeats, transposable elements and their derivatives) embedding a 5S rRNA gene locus (green) as well as their chromatin composition. The pericentromeric domains are enriched in the canonical histone H3.1 (orange), the H2A.W variant (blue) and the linker histone $\mathrm{H} 1$ (pink) as well as in repressive histone modifications such as $\mathrm{H} 3 \mathrm{~K} 9$ me1/me2 and H3K27me1. The centromere is defined by enrichment in the $\mathrm{H} 3$ variant $\mathrm{CenH} 3$ (yellow). Whether CenH3 nucleosomes form large blocks or are interspersed with nucleosomes composed of canonical or specific variant histones and which histones are incorporated as placeholders during replication remains to be determined. CenH3, $\mathrm{H} 1$ and H2A.W are deposited by yet unknown histone chaperones. GIP1/GIP2 and KNL2 play a role in CenH3 deposition. In specific cell types, CenH3 is actively removed by the AAA-ATPase CDC48A. (B) Model of the organization of a chromosome in nuclear space overlaid on a DAPI stained image of an Arabidopsis leaf nucleus. Centromeric and pericentromeric regions of the 5 Arabidopsis chromosomes are tightly packed into chromocenters (red/orange). Chromocenters structure the chromosome in nuclear space by anchoring proximal euchromatic loops, while distal chromosomal regions tend to cluster with telomeres (blue) next to the nucleolus (no). Interactive heterochromatic island (IHI)/KNOT engaged element (KEE) regions, identified in Hi-C maps, form additional intra- and inter-chromosomal contacts (green). Enlargement at the top right shows the nuclear envelope coated internally by a lamina-like structure, which includes CRWN proteins. Chromocenters tend to localize at the nuclear periphery, but the physical link between nuclear envelope components or the nuclear lamina-like components remains to be identified. 
or 180 bp (Kumekawa et al., 2000, 2001; Nagaki et al., 2003) that is arranged in head-to-tail tandem repeats ranging from $\sim 0.4$ to $3 \mathrm{Mb}$ (Figure 1A). The $180 \mathrm{bp}$ repeats are interrupted by a $398 \mathrm{bp}$ fragment of the Athila2 LTR called 106B (Thompson et al., 1996). While highly similar sequences are found on all chromosomes, some 180 bp repeat variants are specific to one centromere (Heslop-Harrison et al., 1999). Centromeres are flanked by a pericentromeric region, which in Arabidopsis contains various types of repeat sequences such as Athila retrotransposons, $500 \mathrm{bp}$ and 160 bp repeats (Bauwens et al., 1991), "Transcriptional Silent Information" (TSI) composed of the $3^{\prime}$ half of an Athila retrotransposon (Steimer et al., 2000) and on some chromosomes the 5S rDNA clusters (Fransz et al., 1998; Cloix et al., 2000). Most repetitive sequences from the pericentromeric region and transposons are kept silent, while others like the 5S rRNA gene clusters (Cloix et al., 2002) are highly transcribed. Despite the efforts in genome assembly (Schneeberger et al., 2011), the establishment of the exact reference sequence for these highly repetitive chromosomal regions remains a challenge for the future.

\section{THE CENTRAL ROLE OF CenH3 IN CENTROMERE DEFINITION}

A high frequency of DNA repeats is not sufficient to define centromeres (Han et al., 2006; Birchler et al., 2010); instead, centromeres are determined by a specific chromatin environment. The basic subunit of chromatin, the nucleosome, comprises 146 bp of DNA that wrap around an octamer of core histones $\mathrm{H} 3, \mathrm{H} 4, \mathrm{H} 2 \mathrm{~A}$, and $\mathrm{H} 2 \mathrm{~B}$. A specific histone variant, called $\mathrm{CenH} 3$, replaces the canonical $\mathrm{H} 3.1$ in centromeric nucleosomes. CenH3 is enriched at $180 \mathrm{bp}$ repeats as shown by Chromatin Immunoprecipitation (ChIP) and Fluorescence in situ hybridization (FISH) experiments (Nagaki et al., 2003; Shibata and Murata, 2004). In agreement with its central role in centromere definition, homozygous cen $\mathrm{H} 3$ mutants are lethal and plants expressing RNAi constructs leading to reduced CenH3 levels show meiosis defects, partial sterility, and in older plants an increased 4C:2C ratio indicating G2 arrest (Lermontova et al., 2011). CenH3 proteins evolve rapidly, as example 23 out of 178 amino acids differ between the closely related species $A$. thaliana and $A$. arenosa (Talbert et al., 2002). The N-terminal tail is substantially longer compared to the canonical H3.1 or the variant $\mathrm{H} 3.3$ and particularly divergent between species, revealing adaptive evolution with the species-specific centromeric repeats (Talbert et al., 2002; Maheshwari et al., 2015). An additional domain involved in adaptive evolution is the histone fold domain including the loop 1 region that makes multiple contacts with DNA (Cooper and Henikoff, 2004). This histone fold domain has been found sufficient for $\mathrm{CenH} 3$ loading at centromeric sequences (Lermontova et al., 2006) and a single point mutation close to the loop1 region reduces $\mathrm{CenH} 3$ loading substantially (Karimi-Ashtiyani et al., 2015). While plants carrying this loading deficient CenH3 are fertile when selfed, backcrossing to wild type (WT) plants leads to haploid and aneuploid progeny, retaining only the $\mathrm{WT}$ CenH3. Unexpectedly, even CenH3 from distant monocotyledon species can complement $A$. thaliana cenh3 mutants (Maheshwari et al., 2015). These results differ from other studies using $\mathrm{N}$-or C-terminal GFP tagged versions of heterologous $\mathrm{CenH} 3$, where only tagged $\mathrm{CenH} 3$ from a closely related species was properly targeted or functionally complemented a cenH3 mutant (Ravi et al., 2010). This shows that a GFP tagged CenH3 version is not functionally equivalent, as the large GFP tag may interfere with proper CenH3 loading or the assembly of kinetochore proteins.

Together, these studies underline a central role for $\mathrm{CenH} 3$ in centromere definition. Fast co-evolution of $\mathrm{CenH} 3$ and centromeric repeats is proposed to contribute to reproductive isolation and speciation (Ma et al., 2007; Plohl et al., 2014). Understanding these key mechanisms may have major application in breeding programs when interspecific crosses between cultivated species and their WT relatives are involved.

\section{CenH3 DEPOSITION}

CenH3 needs to be deposited in a controlled manner to avoid mislocalization to ectopic sites (Lacoste et al., 2014) that might seed neo-centromeres (Shang et al., 2013). Appropriate incorporation of CenH3 is therefore controlled by specific histone chaperones. In mammals, CenH3 is deposited post-mitotically (Jansen et al., 2007), while CenH3 nucleosome assembly takes place in G2 phase in Arabidopsis (Lermontova et al., 2006). In contrast to mitotic nuclei, meiosis includes also a post-divisional loading step during interkinesis (Schubert et al., 2014) and is associated with a specific loading pathway or quality check that eliminates modified CenH3 proteins (Lermontova et al., 2011; Ravi et al., 2011). No functional homolog of CenH3 chaperones known in humans (HJURP, Dunleavy et al., 2009; Foltz et al., 2009), Drosophila (CAL1, Chen et al., 2014) or yeast (SCM3, Camahort et al., 2007) has yet been identified in plants. In contrast, a homolog of yeast Mis18, which is implicated in forming the correct epigenetic context for CenH3 loading (Hayashi et al., 2004), has been identified in Arabidopsis and termed KINETOCHORE NULL2 (KNL2; Lermontova et al., 2013). KNL2 is mainly expressed in meristem tissues similar to $\mathrm{CenH} 3$ and except during mitosis localizes to centromeres during the whole cell cycle including G2 phase when CenH3 is loaded. Loss of KNL2 negatively impacts CenH3 expression and deposition (Lermontova et al., 2013), but also reduces DNA methylation and affects histone methyltransferase expression, suggesting that the chromatin context of centromeric or pericentromeric sequences repeats may play a role in CenH3 loading. Furthermore, recent work suggests a role for the $\gamma$ tubulin complex protein 3-interacting proteins (GIPs) in CenH3 loading or maintenance at centromeres (Batzenschlager et al., 2015). GIP proteins are found in a complex with CenH3 and a double gip1 gip2 mutant shows reduced intensity of CenH3 signals, centromere cohesion defects and aneuploidy, despite increased levels of KNL2 in the gip1 gip2 mutant background (Batzenschlager et al., 2015). Given that the CenH3 deposition machinery evolved rapidly and involves distinct players in yeast, Drosophila, mammals and plants, it can be speculated that GIP proteins are part of a plant-specific pathway contributing to CenH3 assembly.

Interestingly, CenH3 is associated only with specific subsets of $180 \mathrm{bp}$ repeats (Shibata and Murata, 2004) and these are 
hypomethylated (Zhang et al., 2008) compared to other subsets of $180 \mathrm{bp}$ repeats that are hypermethylated, enriched in $\mathrm{H} 3 \mathrm{~K} 9 \mathrm{me} 2$ and associated with the canonical histone H3.1 (Stroud et al., 2012; Wollmann et al., 2012; Vaquero-Sedas and Vega-Palas, 2013). To which extent CenH3 containing nucleosomes are interspersed with nucleosomes containing canonical H3.1 or its variant $\mathrm{H} 3.3$, and which of the CenH3 types is deposited as placeholder upon chromatin assembly during S-phase, remains to be elucidated in plants. Furthermore, the identification of the histone chaperone involved in $\mathrm{CenH} 3$ deposition and further characterization of the role of GIP proteins will be critical to better understand how CenH3 is specifically targeted to centromeric repeats.

While controlled CenH3 deposition is important, in some differentiated cells, CenH3 is also actively removed, such as in the vegetative pollen nucleus that does not contain visible CenH3 enrichment at centromeres compared to the sperm cell nuclei (Ingouff et al., 2009; Schoft et al., 2009). In the vegetative nucleus, CenH3 is sumoylated and removed by the AAA-ATPase molecular chaperone CDC48A to be targeted for proteolysis (Mérai et al., 2014).

\section{THE PERICENTROMERIC REGION}

The CenH3 containing centromere domain is flanked by pericentromeric heterochromatin that is highly DNA methylated, shows more regular nucleosome spacing than euchromatin (Chodavarapu et al., 2010) and is characterized by inaccessibility to DNAse I (Shu et al., 2012). Pericentromeric nucleosomes carry histone modifications repressive for transcription such as H4K20me1, H3K9me1, H3K9me2, and H3K27me1 (Tariq et al., 2003; Naumann et al., 2005; Fransz et al., 2006; Roudier et al., 2011; Shu et al., 2012; Sequeira-Mendes et al., 2014). As an example, $\mathrm{H} 3 \mathrm{~K} 27 \mathrm{me} 1$ loss is associated with release of transcriptional silencing of TSI and certain transposons in the pericentromeric region (Jacob and Feng, 2009) as well as overreplication of pericentromeric sequences (Jacob et al., 2010). The histone-methyltransferases ATXR5 and ATXR6 preferentially mono-methylate lysine 27 of the canonical histone H3.1 (Jacob et al., 2014), which is highly enriched in pericentromeric regions (Vaquero-Sedas and Vega-Palas, 2013). Furthermore, plants deficient in the Chromatin Assembly Factor 1 (CAF-1) complex that deposits histone H3.1 in a replication-coupled manner in mammals (Smith and Stillman, 1989; Tagami et al., 2004) show stochastic reactivation of TSI and CACTA transposable elements (Takeda et al., 2004; Ono et al., 2006). Additional core histones also exist as specialized variants enriched in heterochromatin such as the H2A.W variants H2A.W.6, H2A.W.7 and H2A.W.12 (Yelagandula et al., 2014), which colocalize as RFP fusion proteins with $\mathrm{H} 3 \mathrm{~K} 9 \mathrm{me} 2$ at pericentromeric regions by microscopy. Simultaneous loss of H3K9me2 enhances the phenotype of double h2a.w.6 h2a.w.7 mutants and leads to increased expression of certain transposons suggesting that histone/DNA methylation and $\mathrm{H} 2 \mathrm{~A}$.W incorporation present two parallel pathways involved in heterochromatin maintenance. Therefore, an important role can be assigned to the incorporation of specific histone types in the establishment of the particular chromatin environment of the pericentromeric region. Canonical or histone variants affect chromatin organization both through their inherent physicochemical properties and through their specific post-translational modifications that might be set in a nucleosomal context, e.g., H3K27me1 by ATXR5 and ATXR6 (Jacob et al., 2014), or already during assembly (Loyola et al., 2009) and synthesis (Rivera et al., 2015) of the respective histone as recently described in mammals. Despite the advances in the description of the pericentromeric heterochromatin signature, not much is known whether and how pericentromeric heterochromatin contributes to centromere function in plants. Chromatin or sequence features of the pericentromeric domain may play a role in loading of $\mathrm{CenH} 3$ at the centromere as it is the case in fission yeast (Folco et al., 2008; Catania et al., 2015) but this remains to be investigated.

\section{ORGANIZATION OF CENTROMERIC AND PERICENTROMERIC CHROMATIN INTO CHROMOCENTERS}

In interphase nuclei, FISH experiments indicated that centromeric and pericentromeric repeats cluster together in chromocenter structures (Fransz et al., 2002). Recent Hi-C analyses confirmed that repeated sequences are grouped together and revealed further intra and inter-chromosomal interactions, Figure 1B. Multiple reasons have been brought forward to explain the particular organization of centromeric and pericentromeric sequences into chromocenters: the clustering may compartmentalize silent chromatin away from euchromatin, help concentrate chromatin modifiers setting repressive chromatin marks or coordinate replication of this domain in time and space (Heitz, 1928; Quivy et al., 2004; Almouzni and Probst, 2011). Chromocenters are not randomly organized in nuclear space but instead preferentially localize into the most outer zone next to the nuclear periphery (Fransz et al., 2002; Fang and Spector, 2005; Andrey et al., 2010; Poulet et al., 2015). To date, there is no clear explanation for this preferential localization and several hypotheses can be proposed. First, this organization can be the result of non-specific forces acting on heterochromatin because of its elevated thickness and rigidity in respect to euchromatin (Cook and Marenduzzo, 2009; de Nooijer et al., 2009). Second, peripheral position may be advantageous to allow rapid contact between the centromere and microtubules at the beginning of cell division. Interestingly, GIP proteins have been shown to localize to both sides of the nuclear envelope and close to the chromocenters and may therefore be seen as good candidates to connect the microtubule machinery and the centromeres upon nuclear envelope breakdown (Batzenschlager et al., 2014). The identification of the structural components linking heterochromatin to the nuclear periphery is an active area of research in plants and the lamin-like structures including CRWN1-4 (CRoWded Nuclei) proteins are intriguing candidates (Dittmer et al., 2007; Fiserova et al., 2009; Goto et al., 2014). Indeed, crwn1 crwn 2 mutants show reduced nuclear volume and increased chromocenter clustering, while chromocenters are more dispersed in crwn4 (Dittmer et al., 2007; Wang et al., 2013a; Poulet et al., 2015). Hi-C data in crwn1 and crwn 4 mutants reveal higher chromosomal compaction 
and increased interactions among pericentromeric regions, which reflects the altered chromocenter organization detected by FISH (Grob et al., 2014). Altered chromocenter organization was also observed in syn 4 and cap- $d 3$ mutants, lacking subunits of cohesin or condensin complexes respectively (Schubert et al., 2009, 2013). Given that both CRWN proteins and condensing/cohesion complexes affect chromocenter organization and chromosome compaction it might be interesting to further investigate whether a functional relationship exists between these complexes.

\section{CHROMOCENTER MAINTENANCE AND DYNAMICS}

Mutants impaired in factors involved in setting of epigenetic marks such as DNA methyltransferases (Soppe et al., 2002; Mathieu et al., 2007; Stroud et al., 2014) and histone K27 and K9 methyltransferases (Jacob and Feng, 2009; Yelagandula et al., 2014), in chromatin remodeling (Probst et al., 2003) or in chromatin assembly (Schönrock et al., 2006) affect heterochromatin organization in chromocenters. Furthermore, recent data suggest a role for the histone variant $\mathrm{H} 2 \mathrm{~A} . \mathrm{W}$ in heterochromatin condensation into chromocenters based on its capacity to promote chromatin fiber-to-fiber interactions through its C-terminal end in vitro (Yelagandula et al., 2014) and accordingly $h 2 a . w$ double or triple mutants show chromocenter decondensation. In addition to $\mathrm{H} 2 \mathrm{~A}$.W, the linker histone $\mathrm{H} 1$ facilitates folding of the nucleosome into higher-order structures (Zhou et al., 2013 and references therein). The observation that some plant cells (such as the spore mother cells) show a drastic reduction in chromocenter compaction, concomitantly to $\mathrm{H} 1$ depletion (She et al., 2013; She and Baroux, 2015) suggests a role for the linker histone in pericentromeric chromatin organization, but a causal relationship remains to be established. During development, the organization of centromeric and pericentromeric sequences in chromocenters is dynamic (Benoit et al., 2013). For example during germination, chromocenter organization is lost 1 to 3 days after imbibition and only small and diffuse pre-chromocenters can be detected (van Zanten et al., 2011). Chromocenter assembly then takes place in cotyledons during a short time window between 3 and 5 days after germination (Mathieu et al., 2003; Douet et al., 2008; Bourbousse et al., 2015). Decondensation of chromocenters was also observed at later developmental stages such as during floral transition, when the plant undergoes reprogramming from vegetative to reproductive state, or during protoplast formation, which trigger a partial decondensation of 5S rDNA and 180 bp repeats (Tessadori et al., 2007a,b). Furthermore, the organization of chromocenters dynamically changes upon pathogen infection (Pavet et al., 2006), or under abiotic stresses (Probst and Mittelsten Scheid, 2015). As an example, chromocenters decondense during

\section{REFERENCES}

Almouzni, G., and Probst, A. V. (2011). Heterochromatin maintenance and establishment: lessons from the mouse pericentromere. Nucleus 2, 332-338. doi: 10.4161/nucl.2.5.17707

Andrey, P., Kiêu, K., Kress, C., Lehmann, G., Tirichine, L., Liu, Z., et al. (2010). Statistical analysis of 3D images detects regular spatial distributions of prolonged heat stress (Pecinka et al., 2010), which requires HEATINTOLERANT 4 (HIT4; Wang et al., 2013b). These dynamic changes in chromocenter organization during development or stress might reflect global chromatin changes, revealing the role of chromocenters in the organization of euchromatic loops in nuclear space thereby potentially contributing to gene expression regulation.

\section{A ROLE FOR NON-CODING RNA IN CENTROMERE FUNCTION?}

Centromeric and pericentromeric regions are essential for chromosome segregation in mitosis and meiosis and help to structure chromosomes through the formation of chromocenters in interphase. These are complex functions requesting many factors including specific DNA sequences, deposition of histone variants and epigenetic marks, as well as chromatin organization in nuclear space. While centromeric and pericentromeric regions form a generally repressive chromatin environment, some of these repetitive elements are expressed at low level in specific tissues or developmental stages and processed by the RNAi pathway (May et al., 2005; Slotkin et al., 2009; Slotkin, 2010). In recent years, evidence for RNA in centromere regulation and function accumulated in different organisms (reviewed in Gent et al., 2012). Examples include a role for non-coding RNAs in heterochromatin assembly in fission yeast (Volpe et al., 2002), HP1 recruitment (Maison et al., 2002) and chromocenter organization (Probst et al., 2010) in mammals, as well as CenH3 deposition in mammals and Drosophila (Quénet and Dalal, 2014; Rošić et al., 2014). Furthermore, the passage of RNA polymerase II itself is critical for centromere function (Catania et al., 2015; Chen et al., 2015). Understanding the complex interplay between DNA sequence, transcription, non-coding RNA, chromatin and nuclear environment in centromere function in plants will be a major challenge for the future.

\section{AUTHOR CONTRIBUTIONS}

LS and MV contributed equally to the content and to the drafting of the manuscript. CT and AP edited the manuscript. All authors read and approved the manuscript.

\section{ACKNOWLEDGMENTS}

This work was supported by INSERM, CNRS and Clermont universities, by the French National Research Agency (ANR-11 JSV2 009 01, ANR-12-ISV6-0001 to AVP) and by the Region Auvergne and FEDER (Life GRID to CT). LS was supported by a $\mathrm{PhD}$ fellowship from the Region Auvergne.

centromeres and chromocenters in animal and plant nuclei. PLoS Comput. Biol. 6:27. doi: 10.1371/journal.pcbi.1000853

Batzenschlager, M., Herzog, E., Houlné, G., Schmit, A.-C., and Chabouté, M.-E. (2014). GIP/MZT1 proteins orchestrate nuclear shaping. Front. Plant Sci. 5:29. doi: $10.3389 /$ fpls.2014.00029

Batzenschlager, M., Lermontova, I., Schubert, V., Fuchs, J., Berr, A., Koini, M. A., et al. (2015). Arabidopsis MZT1 homologs GIP1 and GIP2 are essential 
for centromere architecture. Proc. Natl. Acad. Sci. U.S.A. 112, 8656-8660. doi: 10.1073/pnas.1506351112

Bauwens, S., Van Oostveldt, P., Engler, G., and Van Montagu, M. (1991). Distribution of the rDNA and three classes of highly repetitive DNA in the chromatin of interphase nuclei of Arabidopsis thaliana. Chromosoma 101, 41-48.

Benoit, M., Layat, E., Tourmente, S., and Probst, A. V. (2013). Heterochromatin dynamics during developmental transitions in Arabidopsis-a focus on ribosomal DNA loci. Gene 526, 39-45. doi: 10.1016/j.gene.2013.01.060

Birchler, J. A., Krishnaswamy, L., Gaeta, R. T., Masonbrink, R. E., and Zhao, C. (2010). Engineered minichromosomes in plants. CRC. Crit. Rev. Plant Sci. 29, 135-147. doi: 10.1080/07352681003709918

Bourbousse, C., Mestiri, I., Zabulon, G., Bourge, M., Formiggini, F., Koini, M. A., et al. (2015). Light signaling controls nuclear architecture reorganization during seedling establishment. Proc. Natl. Acad. Sci. U.S.A. 112, E2836-E2844. doi: 10.1073/pnas.1503512112

Camahort, R., Li, B., Florens, L., Swanson, S. K., Washburn, M. P., and Gerton, J. L. (2007). Scm 3 is essential to recruit the histone $\mathrm{h} 3$ variant cse4 to centromeres and to maintain a functional kinetochore. Mol. Cell 26, 853-865. doi: 10.1016/j.molcel.2007.05.013

Catania, S., Pidoux, A. L., and Allshire, R. C. (2015). Sequence features and transcriptional stalling within centromere DNA promote establishment of CENP-A chromatin. PLoS Genet. 11:e1004986. doi: 10.1371/journal.pgen.1004986

Chen, C.-C., Bowers, S., Lipinszki, Z., Palladino, J., Trusiak, S., Bettini, E., et al. (2015). Establishment of centromeric chromatin by the CENP-A assembly factor CAL1 requires FACT-mediated transcription. Dev. Cell 34, 73-84. doi: 10.1016/j.devcel.2015.05.012

Chen, C. C., Dechassa, M. L., Bettini, E., Ledoux, M. B., Belisario, C., Heun, P., et al. (2014). CAL1 is the Drosophila CENP-A assembly factor. J. Cell Biol. 204, 313-329. doi: $10.1083 /$ jcb. 201305036

Chodavarapu, R. K., Feng, S., Bernatavichute, Y. V., Chen, P.-Y., Stroud, H., Yu, Y., et al. (2010). Relationship between nucleosome positioning and DNA methylation. Nature 466, 388-392. doi: 10.1038/nature09147

Cloix, C., Tutois, S., Mathieu, O., Cuvillier, C., Espagnol, M. C., Picard, G., et al. (2000). Analysis of 5S rDNA arrays in Arabidopsis thaliana: physical mapping and chromosome-specific polymorphisms. Genome Res. 10, 679-690. doi: $10.1101 /$ gr.10.5.679

Cloix, C., Tutois, S., Yukawa, Y., Mathieu, O., Cuvillier, C., Espagnol, M.-C., et al. (2002). Analysis of the 5S RNA pool in Arabidopsis thaliana: RNAs Are heterogeneous and only two of the genomic 5S loci produce mature 5S RNA. Genome Res. 12, 132-144. doi: 10.1101/gr.181301

Cook, P. R., and Marenduzzo, D. (2009). Entropic organization of interphase chromosomes. J. Cell Biol. 186, 825-834. doi: 10.1083/jcb.200903083

Cooper, J. L., and Henikoff, S. (2004). Adaptive evolution of the histone fold domain in centromeric histones. Mol. Biol. Evol. 21, 1712-1718. doi: $10.1093 / \mathrm{molbev} / \mathrm{msh} 179$

de Nooijer, S., Wellink, J., Mulder, B., and Bisseling, T. (2009). Non-specific interactions are sufficient to explain the position of heterochromatic chromocenters and nucleoli in interphase nuclei. Nucleic Acids Res. 37, 3558-3568. doi: 10.1093/nar/gkp219

Dittmer, T. A., Stacey, N. J., Sugimoto-Shirasu, K., and Richards, E. J. (2007). LITTLE NUCLEI genes affecting nuclear morphology in Arabidopsis thaliana. Plant Cell 19, 2793-2803. doi: 10.1105/tpc.107.053231

Douet, J., Blanchard, B., Cuvillier, C., and Tourmente, S. (2008). Interplay of RNA Pol IV and ROS1 during post-embryonic 5S rDNA chromatin remodeling. Plant Cell Physiol. 49, 1783-1791. doi: 10.1093/pcp/pcn152

Dunleavy, E. M., Roche, D., Tagami, H., Lacoste, N., Ray-Gallet, D., Nakamura, Y., et al. (2009). HJURP Is a cell-cycle-dependent maintenance and deposition factor of CENP-A at centromeres. Cell 137, 485-497. doi: 10.1016/j.cell.2009. 02.040

Fang, Y., and Spector, D. L. (2005). Centromere positioning and dynamics in living Arabidopsis plants. Mol. Biol. Cell 16, 5710-5718. doi: 10.1091/mbc.E05-08-0706

Fiserova, J., Kiseleva, E., and Goldberg, M. W. (2009). Nuclear envelope and nuclear pore complex structure and organization in tobacco BY-2 cells. Plant J. 59, 243-255. doi: 10.1111/j.1365-313X.2009.03865.x

Folco, H. D., Pidoux, A. L., Urano, T., and Allshire, R. C. (2008). Heterochromatin and RNAi are required to establish CENP-A chromatin at centromeres. Science 319, 94-97. doi: 10.1126/science.1150944
Foltz, D. R., Jansen, L. E. T., Bailey, A. O., Yates, J. R., Bassett, E. A., Wood, S., et al. (2009). Centromere-specific assembly of CENP-A nucleosomes is mediated by HJURP. Cell 137, 472-484. doi: 10.1016/j.cell.2009.02.039

Fransz, P. F., Armstrong, S., Alonso-Blanco, C., Fischer, T. C., Torres-Ruiz, R. A., and Jones, G. (1998). Cytogenetics for the model system Arabidopsis thaliana. Plant J. 13, 867-876.

Fransz, P. F., De Jong, J. H., Lysak, M., Castiglione, M. R., and Schubert, I. (2002). Interphase chromosomes in Arabidopsis are organized as well defined chromocenters from which euchromatin loops emanate. Proc. Natl. Acad. Sci. U.S.A. 99, 14584-14589. doi: 10.1073/pnas.212325299

Fransz, P. F., ten Hoopen, R., and Tessadori, F. (2006). Composition and formation of heterochromatin in Arabidopsis thaliana. Chromosom. Res. 14, 71-82. doi: 10.1007/s10577-005-1022-5

Gent, J. I., and Dawe, R. K. (2011). RNA as a structural and regulatory component of the centromere. Annu. Rev. Genet. 46, 443-453. doi: 10.1146/annurev-genet110711-155419

Gent, J. I., Dong, Y., Jiang, J., and Dawe, R. K. (2012). Strong epigenetic similarity between maize centromeric and pericentromeric regions at the level of small RNAs, DNA methylation and H3 chromatin modifications. Nucleic Acids Res. 40, 1550-1560. doi: 10.1093/nar/gkr862

Goto, C., Tamura, K., Fukao, Y., Shimada, T., and Hara-Nishimura, I. (2014). The novel nuclear envelope protein KAKU4 modulates nuclear morphology in Arabidopsis. Plant Cell 26, 2143-2155. doi: 10.1105/tpc.113.122168

Grob, S., Schmid, M. W., and Grossniklaus, U. (2014). Hi-C analysis in Arabidopsis identifies the KNOT, a structure with similarities to the flamenco locus of drosophila. Mol. Cell 55, 678-679. doi: 10.1016/j.molcel.2014.07.009

Han, F., Lamb, J. C., and Birchler, J. A. (2006). High frequency of centromere inactivation resulting in stable dicentric chromosomes of maize. Proc. Natl. Acad. Sci. U.S.A. 103, 3238-3243. doi: 10.1073/pnas. 0509650103

Han, Y., Zhang, Z., Liu, C., Liu, J., Huang, S., Jiang, J., et al. (2009). Centromere repositioning in cucurbit species: implication of the genomic impact from centromere activation and inactivation. Proc. Natl. Acad. Sci. U.S.A. 106, 14937-14941. doi: 10.1073/pnas.0904833106

Hayashi, T., Fujita, Y., Iwasaki, O., Adachi, Y., Takahashi, K., and Yanagida, M. (2004). Mis16 and Mis18 are required for CENP-A loading and histone deacetylation at centromeres. Cell 118, 715-729. doi: 10.1016/j.cell.2004.09.002

Heitz, E. (1928). Das heterochromatin der Moose. Jahrb Wiss Bot. 69, 762-818.

Heslop-Harrison, J. S., Murata, M., Ogura, Y., Schwarzacher, T., and Motoyoshi, F. (1999). Polymorphisms and genomic organization of repetitive DNA from centromeric regions of Arabidopsis chromosomes. Plant Cell 11, 31-42. doi: 10.1105/tpc.11.1.31

Ingouff, M., Sakata, T., Li, J., Sprunck, S., Dresselhaus, T., and Berger, F. (2009). The two male gametes share equal ability to fertilize the egg cell in Arabidopsis thaliana. Curr. Biol. 19, 19-20. doi: 10.1016/j.cub.2008.11.025

Jacob, Y., Bergamin, E., Donoghue, M. T. A., Mongeon, V., LeBlanc, C., Voigt, P., et al. (2014). Selective methylation of histone H3 variant H3.1 regulates heterochromatin replication. Science 343, 1249-1253. doi: 10.1126/science. 1248357

Jacob, Y., and Feng, S. (2009). ATXR5 and ATXR6 are H3K27 monomethyltransferases required for chromatin structure and gene silencing. Nat. Struct. 16, 763-768. doi: 10.1038/nsmb.1611

Jacob, Y., Stroud, H., Leblanc, C., Feng, S., Zhuo, L., Caro, E., et al. (2010). Regulation of heterochromatic DNA replication by histone $\mathrm{H} 3$ lysine 27 methyltransferases. Nature 466, 987-991. doi: 10.1038/nature09290

Jansen, L. E. T., Black, B. E., Foltz, D. R., and Cleveland, D. W. (2007). Propagation of centromeric chromatin requires exit from mitosis. J. Cell Biol. 176, 795-805. doi: $10.1083 /$ jcb.200701066

Karimi-Ashtiyani, R., Ishii, T., Niessen, M., Stein, N., Heckmann, S., Gurushidze, M., et al. (2015). Point mutation impairs centromeric CENH3 loading and induces haploid plants. Proc. Natl. Acad. Sci. U.S.A. 201504333. doi: $10.1073 /$ pnas. 1504333112

Kumekawa, N., Hosouchi, T., Tsuruoka, H., and Kotani, H. (2000). The size and sequence organization of the centromeric region of Arabidopsis thaliana chromosome 5. DNA Res. 7, 315-321. doi: 10.1093/dnares/7.6.315

Kumekawa, N., Hosouchi, T., Tsuruoka, H., and Kotani, H. (2001). The size and sequence organization of the centromeric region of Arabidopsis thaliana chromosome 4. DNA Res. 8, 285-290. doi: 10.1093/dnares/8.6.285

Lacoste, N., Woolfe, A., Tachiwana, H., Garea, A. V., Barth, T., Cantaloube, S., et al. (2014). Mislocalization of the centromeric histone variant CenH3/CENP-A 
in human cells depends on the chaperone DAXX. Mol. Cell 53, 631-644. doi: 10.1016/j.molcel.2014.01.018

Lermontova, I., Koroleva, O., Rutten, T., Fuchs, J., Schubert, V., Moraes, I., et al. (2011). Knockdown of CENH3 in Arabidopsis reduces mitotic divisions and causes sterility by disturbed meiotic chromosome segregation. Plant J. 68, 40-50. doi: 10.1111/j.1365-313X.2011.04664.x

Lermontova, I., Kuhlmann, M., Friedel, S., Rutten, T., Heckmann, S., Sandmann, M., et al. (2013). Arabidopsis kinetochore null2 is an upstream component for centromeric histone $\mathrm{H} 3$ variant cenH3 deposition at centromeres. Plant Cell 25, 3389-3404. doi: 10.1105/tpc.113.114736

Lermontova, I., Schubert, V., Fuchs, J., Klatte, S., Macas, J., and Schubert, I. (2006). Loading of Arabidopsis centromeric histone CENH3 occurs mainly during G2 and requires the presence of the histone fold domain. Plant Cell 18, 2443-2451. doi: 10.1105/tpc.106.043174

Loyola, A., Tagami, H., Bonaldi, T., Roche, D., Quivy, J. P., Imhof, A., et al. (2009). The HP1alpha-CAF1-SetDB1-containing complex provides H3K9mel for Suv39-mediated $\mathrm{K} 9 \mathrm{me} 3$ in pericentric heterochromatin. EMBO Rep. 10, 769-775. doi: 10.1038/embor.2009.90

Ma, J., Wing, R. A., Bennetzen, J. L., and Jackson, S. A. (2007). Plant centromere organization: a dynamic structure with conserved functions. Trends Genet. 23, 134-139. doi: 10.1016/j.tig.2007.01.004

Maheshwari, S., Tan, E. H., West, A., Franklin, F. C. H., Comai, L., and Chan, S. W. L. (2015). Naturally occurring differences in CENH3 affect chromosome segregation in zygotic mitosis of hybrids. PLoS Genet. 11:e1004970. doi: 10.1371/journal.pgen.1004970

Maison, C., Bailly, D., Peters, A. H. F. M., Quivy, J.-P., Roche, D., Taddei, A., et al. (2002). Higher-order structure in pericentric heterochromatin involves a distinct pattern of histone modification and an RNA component. Nat. Genet. 30, 329-334. doi: 10.1038/ng843

Mathieu, O., Jasencakova, Z., Vaillant, I., Gendrel, A.-V., Colot, V., Schubert, I., et al. (2003). Changes in 5 SDNA chromatin organization and transcription during heterochromatin establishment in Arabidopsis. Plant Cell 15, 2929-2939. doi: $10.1105 /$ tpc. 017467

Mathieu, O., Reinders, J., Čaikovski, M., Smathajitt, C., and Paszkowski, J. (2007). Transgenerational stability of the Arabidopsis epigenome is coordinated by CG methylation. Cell 130, 851-862. doi: 10.1016/j.cell.2007.07.007

May, B. P., Lippman, Z. B., Fang, Y., Spector, D. L., and Martienssen, R. a. (2005). Differential regulation of strand-specific transcripts from Arabidopsis centromeric satellite repeats. PLoS Genet. 1:e79. doi: 10.1371/journal.pgen.0010079

Mérai, Z., Chumak, N., García-Aguilar, M., Hsieh, T.-F., Nishimura, T., Schoft, V. K., et al. (2014). The AAA-ATPase molecular chaperone Cdc48/p97 disassembles sumoylated centromeres, decondenses heterochromatin, and activates ribosomal RNA genes. Proc. Natl. Acad. Sci. U.S.A. 111, 16166-16171. doi: $10.1073 /$ pnas.1418564111

Nagaki, K., Talbert, P. B., Zhong, C. X., Dawe, R. K., Henikoff, S., and Jiang, J. (2003). Chromatin immunoprecipitation reveals that the 180-bp satellite repeat is the key functional DNA element of Arabidopsis thaliana centromeres. Genetics 163, $1221-1225$.

Naumann, K., Fischer, A., Hofmann, I., Krauss, V., Phalke, S., Irmler, K., et al. (2005). Pivotal role of AtSUVH2 in heterochromatic histone methylation and gene silencing in Arabidopsis. EMBO J. 24, 1418-1429. doi: 10.1038/sj.emboj.7600604

Ono, T., Kaya, H., Takeda, S., Abe, M., Ogawa, Y., Kato, M., et al. (2006). Chromatin assembly factor 1 ensures the stable maintenance of silent chromatin states in Arabidopsis. Genes Cells 11, 153-162. doi: 10.1111/j.1365-2443.2006.00928.x

Pavet, V., Quintero, C., Cecchini, N. M., Rosa, A. L., and Alvarez, M. E. (2006). Arabidopsis displays centromeric DNA hypomethylation and cytological alterations of heterochromatin upon attack by Pseudomonas syringae. Mol. Plant Microbe Interact. 19, 577-587. doi: 10.1094/MPMI-19-0577

Pecinka, A., Dinh, H. Q., Baubec, T., Rosa, M., Lettner, N., and Scheid, O. M. (2010). Epigenetic regulation of repetitive elements is attenuated by prolonged heat stress in Arabidopsis. Plant Cell 22, 3118-3129. doi: 10.1105/tpc.110. 078493

Plohl, M., Meštrović, N., and Mravinac, B. (2014). Centromere identity from the DNA point of view. Chromosoma 123, 313-325. doi: 10.1007/s00412-014-0462-0

Poulet, A., Arganda-Carreras, I., Legland, D., Probst, A. V., Andrey, P., and Tatout, C. (2015). NucleusJ: an ImageJ plugin for quantifying 3D images of interphase nuclei. Bioinformatics 31, 1144-1146. doi: 10.1093/bioinformatics/btu774
Probst, A. V., Fransz, P. F., Paszkowski, J., and Mittelsten Scheid, O. (2003). Two means of transcriptional reactivation within heterochromatin. Plant J. cell Mol. Biol. 33, 743-749. doi: 10.1046/j.1365-313X.2003.01667.x

Probst, A. V., and Mittelsten Scheid, O. (2015). Stress-induced structural changes in plant chromatin. Curr. Opin. Plant Biol. 27, 8-16. doi: 10.1016/j.pbi.2015.05.011

Probst, A. V., Okamoto, I., Casanova, M., El Marjou, F., Le Baccon, P., and Almouzni, G. (2010). A strand-specific burst in transcription of pericentric satellites is required for chromocenter formation and early mouse development. Dev. Cell 19, 625-638. doi: 10.1016/j.devcel.2010.09.002

Quénet, D., and Dalal, Y. (2014). A long non-coding RNA is required for targeting centromeric protein A to the human centromere. Elife 3, e03254. doi: 10.7554/eLife.03254

Quivy, J.-P., Roche, D., Kirschner, D., Tagami, H., Nakatani, Y., and Almouzni, G. (2004). A CAF-1 dependent pool of HP1 during heterochromatin duplication. EMBO J. 23, 3516-3526. doi: 10.1038/sj.emboj.7600362

Ravi, M., Kwong, P. N., Menorca, R. M. G., Valencia, J. T., Ramahi, J. S., Stewart, J. L., et al. (2010). The rapidly evolving centromere-specific histone has stringent functional requirements in Arabidopsis thaliana. Genetics 186, 461-471. doi: 10.1534/genetics.110.120337

Ravi, M., Shibata, F., Ramahi, J. S., Nagaki, K., Chen, C., Murata, M., et al. (2011). Meiosis-specific loading of the centromere-specific histone CENH3 in Arabidopsis thaliana. PLoS Genet. 7:e1002121. doi: 10.1371/journal.pgen.1002121

Rivera, C., Saavedra, F., Alvarez, F., Díaz-Celis, C., Ugalde, V., Li, J., et al. (2015). Methylation of histone H3 lysine 9 occurs during translation. Nucleic Acids Res. 43, 9097-9106. doi: 10.1093/nar/gkv929

Rošić, S., Köhler, F., and Erhardt, S. (2014). Repetitive centromeric satellite RNA is essential for kinetochore formation and cell division. J. Cell Biol. 207, 335-349. doi: $10.1083 /$ jcb. 201404097

Roudier, F., Ahmed, I., Bérard, C., Sarazin, A., Mary-Huard, T., Cortijo, S., et al. (2011). Integrative epigenomic mapping defines four main chromatin states in Arabidopsis. EMBO J. 30, 1928-1938. doi: 10.1038/emboj.2011. 103

Schneeberger, K., Ossowski, S., Ott, F., Klein, J. D., Wang, X., Lanz, C., et al. (2011). Reference-guided assembly of four diverse Arabidopsis thaliana genomes. Proc. Natl. Acad. Sci. U.S.A. 108, 10249-10254. doi: 10.1073/pnas.1107739108

Schoft, V. K., Chumak, N., Mosiolek, M., Slusarz, L., Komnenovic, V., Brownfield, L., et al. (2009). Induction of RNA-directed DNA methylation upon decondensation of constitutive heterochromatin. EMBO Rep. 10, 1015-1021. doi: 10.1038/embor.2009.152

Schönrock, N., Exner, V., Probst, A., Gruissem, W., and Hennig, L. (2006). Functional genomic analysis of CAF-1 mutants in Arabidopsis thaliana. J. Biol. Chem. 281, 9560-9568. doi: 10.1074/jbc.M513426200

Schubert, V., Lermontova, I., and Schubert, I. (2013). The Arabidopsis CAP-D proteins are required for correct chromatin organisation, growth and fertility. Chromosoma 122, 517-533. doi: 10.1007/s00412-013-0424-y

Schubert, V., Lermontova, I., and Schubert, I. (2014). Loading of the centromeric histone $\mathrm{H} 3$ variant during meiosis-how does it differ from mitosis? Chromosoma 123, 491-497. doi: 10.1007/s00412-014-0466-9

Schubert, V., Weißleder, A., Ali, H., Fuchs, J., Lermontova, I., Meister, A., et al. (2009). Cohesin gene defects may impair sister chromatid alignment and genome stability in Arabidopsis thaliana. Chromosoma 118, 591-605. doi: 10.1007/s00412-009-0220-x

Sequeira-Mendes, J., Aragüez, I., Peiró, R., Mendez-Giraldez, R., Zhang, X., Jacobsen, S. E., et al. (2014). The functional topography of the Arabidopsis genome is organized in a reduced number of linear motifs of chromatin states. Plant Cell. 26, 2351-2366. doi: 10.1105/tpc.114.124578

Shang, W.-H., Hori, T., Martins, N. M. C., Toyoda, A., Misu, S., Monma, N., et al. (2013). Chromosome engineering allows the efficient isolation of vertebrate neocentromeres. Dev. Cell 24, 635-648. doi: 10.1016/j.devcel.2013. 02.009

She, W., and Baroux, C. (2015). Chromatin dynamics in pollen mother cells underpin a common scenario at the somatic-to-reproductive fate transition of both the male and female lineages in Arabidopsis. Front. Plant Sci. 6:294. doi: 10.3389/fpls.2015.00294

She, W., Grimanelli, D., Rutowicz, K., Whitehead, M. W. J., Puzio, M., Kotlinski, M., et al. (2013). Chromatin reprogramming during the somatic-to-reproductive cell fate transition in plants. Development 140, 4008-4019. doi: 10.1242/dev. 095034 
Shibata, F., and Murata, M. (2004). Differential localization of the centromerespecific proteins in the major centromeric satellite of Arabidopsis thaliana. J. Cell Sci. 117, 2963-2970. doi: 10.1242/jcs.01144

Shu, H., Wildhaber, T., Siretskiy, A., Gruissem, W., and Hennig, L. (2012). Distinct modes of DNA accessibility in plant chromatin. Nat. Commun. 3, 1281. doi: $10.1038 /$ ncomms 2259

Slotkin, R. K. (2010). The epigenetic control of the athila family of retrotransposons in Arabidopsis. Epigenetics 5, 483-490. doi: 10.4161/epi.5.6.12119

Slotkin, R. K., Vaughn, M., Borges, F., Tanurdzić, M., Becker, J. D., Feijó, J. A., et al. (2009). Epigenetic reprogramming and small RNA silencing of transposable elements in pollen. Cell 136, 461-472. doi: 10.1016/j.cell.2008.12.038

Smith, S., and Stillman, B. (1989). Purification and characterization of CAF-I, a human cell factor required for chromatin assembly during DNA replication in vitro. Cell 58, 15-25. doi: 10.1016/0092-8674(89)90398-X

Soppe, W. J. J., Jasencakova, Z., Houben, A., Kakutani, T., Meister, A., Huang, M. S., et al. (2002). DNA methylation controls histone H3 lysine 9 methylation and heterochromatin assembly in Arabidopsis. EMBO J. 21, 6549-6559. doi: 10.1093/emboj/cdf657

Steimer, A., Amedeo, P., Afsar, K., Fransz, P. F., Mittelsten Scheid, O., and Paszkowski, J. (2000). Endogenous targets of transcriptional gene silencing in Arabidopsis. Plant Cell 12, 1165-1178. doi: 10.1105/tpc.12.7.1165

Stroud, H., Do, T., Du, J., Zhong, X., Feng, S., Johnson, L., et al. (2014). Non-CG methylation patterns shape the epigenetic landscape in Arabidopsis. Nat. Struct. Mol. Biol. 21, 64-72. doi: 10.1038/nsmb.2735

Stroud, H., Otero, S., Desvoyes, B., Ramirez-Parra, E., Jacobsen, S. E., and Gutierrez, C. (2012). Genome-wide analysis of histone H3.1 and H3.3 variants in Arabidopsis thaliana. Proc. Natl. Acad. Sci. U.S.A. 109, 5370-5375. doi: 10.1073/pnas.1203145109

Tagami, H., Ray-Gallet, D., Almouzni, G., and Nakatani, Y. (2004). Histone H3.1 and H3.3 complexes mediate nucleosome assembly pathways dependent or independent of DNA synthesis. Cell 116, 51-61. doi: 10.1016/S00928674(03)01064-X

Takeda, S., Tadele, Z., Hofmann, I., Probst, A. V., Angelis, K. J., Kaya, H., et al. (2004). BRU1, a novel link between responses to DNA damage and epigenetic gene silencing in Arabidopsis. Genes Dev. 18, 782-793. doi: 10.1101/gad.295404

Talbert, P. B., Masuelli, R., Tyagi, A. P., Comai, L., and Henikoff, S. (2002). Centromeric localization and adaptive evolution of an Arabidopsis histone H3 variant. Plant Cell 14, 1053-1066. doi: 10.1105/tpc.010425

Tariq, M., Saze, H., Probst, A. V., Lichota, J., Habu, Y., and Paszkowski, J. (2003). Erasure of CpG methylation in Arabidopsis alters patterns of histone $\mathrm{H} 3$ methylation in heterochromatin. Proc. Natl. Acad. Sci. U.S.A. 100, 8823-8827. doi: 10.1073/pnas.1432939100

Tessadori, F., Chupeau, M.-C., Chupeau, Y., Knip, M., Germann, S., van Driel, R., et al. (2007a). Large-scale dissociation and sequential reassembly of pericentric heterochromatin in dedifferentiated Arabidopsis cells. J. Cell Sci. 120, 1200-1208. doi: 10.1242/jcs.000026

Tessadori, F., Schulkes, R. K., Van Driel, R., and Fransz, P. (2007b). Lightregulated large-scale reorganization of chromatin during the floral transition in Arabidopsis. Plant J. 50, 848-857. doi: 10.1111/j.1365-313X.2007. 03093.x

Thompson, H. L., Schmidt, R., and Dean, C. (1996). Identification and distribution of seven classes of middle-repetitive DNA in the Arabidopsis thaliana genome. Nucleic Acids Res. 24, 3017-3022.

van Zanten, M., Koini, M. A., Geyer, R., Liu, Y., Brambilla, V., Bartels, D., et al. (2011). Seed maturation in Arabidopsis thaliana is characterized by nuclear size reduction and increased chromatin condensation. Proc. Natl. Acad. Sci. U.S.A. 108, 20219-20224. doi: 10.1073/pnas.1117726108

Vaquero-Sedas, M. I., and Vega-Palas, M. A. (2013). Differential association of Arabidopsis telomeres and centromeres with histone H3 variants. Sci. Rep. 3, 1202. doi: 10.1038/srep01202

Volpe, T. A., Kidner, C., Hall, I. M., Teng, G., Grewal, S. I. S., and Martienssen, R. A. (2002). Regulation of heterochromatic silencing and histone H3 lysine-9 methylation by RNAi. Science 297, 1833-1837. doi: 10.1126/science.1074973

Wang, H., Dittmer, T. A., and Richards, E. J. (2013a). Arabidopsis CROWDED NUCLEI (CRWN) proteins are required for nuclear size control and heterochromatin organization. BMC Plant Biol. 13:200. doi: 10.1186/1471-222913-200

Wang, L.-C., Wu, J.-R., Chang, W.-L., Yeh, C.-H., Ke, Y.-T., Lu, C.-A., et al. (2013b). Arabidopsis HIT4 encodes a novel chromocentre-localized protein involved in the heat reactivation of transcriptionally silent loci and is essential for heat tolerance in plants. J. Exp. Bot. 64, 1689-1701. doi: 10.1093/jxb/ert030

Wollmann, H., Holec, S., Alden, K., Clarke, N. D., Jacques, P.-E., and Berger, F. (2012). Dynamic deposition of histone variant H3.3 accompanies developmental remodeling of the Arabidopsis transcriptome. PLoS Genet. 8:e1002658. doi: 10.1371/journal.pgen.1002658

Yelagandula, R., Stroud, H., Holec, S., Zhou, K., Feng, S., Zhong, X., et al. (2014). The histone variant $\mathrm{H} 2 \mathrm{~A}$.W defines heterochromatin and promotes chromatin condensation in Arabidopsis. Cell 158, 98-109. doi: 10.1016/j.cell.2014. 06.006

Zhang, W., Lee, H.-R., Koo, D.-H., and Jiang, J. (2008). Epigenetic modification of centromeric chromatin: hypomethylation of DNA sequences in the CENH3associated chromatin in Arabidopsis thaliana and maize. Plant Cell 20, 25-34. doi: 10.1105/tpc.107.057083

Zhou, B., Feng, H., and Kato, H. (2013). Structural insights into the histone H1nucleosome complex. Proc. Natl. Acad. Sci. U.S.A. 111, 1222.

Conflict of Interest Statement: The authors declare that the research was conducted in the absence of any commercial or financial relationships that could be construed as a potential conflict of interest.

Copyright (C) 2015 Simon, Voisin, Tatout and Probst. This is an open-access article distributed under the terms of the Creative Commons Attribution License (CC BY). The use, distribution or reproduction in other forums is permitted, provided the original author(s) or licensor are credited and that the original publication in this journal is cited, in accordance with accepted academic practice. No use, distribution or reproduction is permitted which does not comply with these terms. 